\title{
Educação permanente na atenção secundária: Uma estratégia para elaboração do protocolo de atendimento à urgência
}

\author{
Continuing education in secondary care: A strategy for the elaboration of the urgency care protocol \\ Educación continua en atención secundaria: una estrategia para la elaboración del protocolo de
}

atención de urgencia

Recebido: 06/12/2021 | Revisado: 10/12/2021 | Aceito: 18/12/2021 | Publicado: 02/01/2022

\author{
José Eduardo da Costa Gircys \\ ORCID: https://orcid.org/0000-0001-6331-1808 \\ Universidade Federal Fluminense, Brasil \\ E-mail: jeircys@yahoo.com.br \\ Karen Strong Ferreira Teixeira \\ ORCID: https://orcid.org/0000-0001-8457-667X \\ Universidade Federal Fluminense, Brasil \\ E-mail:karenstrong@zipmail.com.br \\ Marcos Paulo Fonseca Corvino \\ ORCID: https://orcid.org/0000-0001-9043-730X \\ Universidade Federal Fluminense, Brasil \\ E-mail: corvinomarcos@id.uff.br \\ Geilsa Soraia Cavalcanti Valente \\ ORCID: https://orcid.org/0000-0003-4488-4912 \\ Universidade Federal Fluminense, Brasil \\ E-mail:geilsavalente@gmail.com
}

\begin{abstract}
Resumo
O processo de trabalho no SUS para ser constituído de forma a permitir a melhor interação interprofissional, requer o exercício cotidiano da Educação Permanente em Saúde. Caso contrário, nos deparamos em ambiente multiprofissional, deficiente e carente de mudanças, isolados, podendo gerar falta de estímulo aos profissionais envolvidos, e repercutindo aos usuários do SUS, devendo ser repensado. Na Atenção Secundária, verificamos uma limitada atividade prática da Educação Permanente em Saúde, devendo ser incentivada e experimentada no processo vivo do trabalho cotidiano. Este artigo, propõe uma reflexão sobre a prática individual do profissional, e mais do que sua interação multiprofissional no processo de trabalho, relata uma experiência positiva originada da atuação em processo de Educação Permanente na Atenção Secundária da região serrana do estado do Rio de Janeiro. Esse processo foi enriquecido mediante elaboração de protocolo de atendimento a pacientes com nível de consciência reduzido, adequado à realidade local, produto da demanda do grupo de trabalho.

Palavras-chave: Educação permanente em saúde, Multiprofissionalidade; Interprofissionalidade; Atenção secundária; Problematização/aprendizagem significativa; Protocolo.
\end{abstract}

\begin{abstract}
The work process in the SUS, to be constituted in a way that allows the best interprofessional interaction, requires the daily exercise of Continuing Education in our Health Units. Otherwise, we find ourselves in a multidisciplinary environment, deficient and in need of change, isolated, which can generate lack of encouragement to the professionals involved, and reflecting on SUS users, which should be rethought. In Secondary Care, we found a limited practical activity of Continuing Education in Health, which should be encouraged and experienced in the living process of daily work. This article proposes a reflection on the professional's individual practice, and more than his multidisciplinary interaction in the work process, but at the same time reports a positive experience arising from the performance of Continuing Education in Health Units in the Secondary Care service of the region. mountains of the state of Rio de Janeiro, through the elaboration of a protocol for the care of patients with reduced level of consciousness, adequate to the local reality, product of the demand of the work group.
\end{abstract}

Keywords: Continuing education in health; Multidisciplinary; Interprofessionality; Secondary care; Problematization/significant learning; Protocol.

\section{Resumen}

El proceso de trabajo en el SUS, para que se constituya de manera que permita la mejor interacción interprofesional, requiere el ejercicio diario de la Educación Permanente en Salud, a los profesionales involucrados, y la reflexión sobre 
los usuarios del SUS, lo cual debe ser repensado. En la Educación Secundaria se constató una limitada actividad práctica de Educación Permanente en Salud, la cual debe ser incentivada y experimentada en el proceso vital del trabajo diario. Este artículo propone una reflexión sobre la práctica individual del profesional, y más que su interacción multiprofesional en el proceso de trabajo, reporta una experiencia positiva derivada del desempeño en el proceso de Educación Permanente en Atención Secundaria en la región montañosa del estado de Río de Janeiro. Este proceso se enriqueció mediante la elaboración de un protocolo de atención a pacientes con nivel reducido de conciencia, adecuado a la realidad local, producto de la demanda del grupo de trabajo.

Palabras clave: Educación continuada en salud; Multidisciplinar; Interprofesionalidad; Atención secundaria; Problematización/aprendizaje significativo; Protocolo.

\section{Introdução}

As Doenças Crônicas e as DCNTs demandam ações conjuntas da Atenção Primária, Secundária e Terciária em Saúde, com o objetivo de acompanhar o usuário neste caminhar na Rede de Atenção à Saúde (RAS) para que seja atingida a integralidade do cuidado (Brondani, Leal, Potter, Silva, Noal, \& Perrando, 2016).

Diante disso, foi lançado o Plano de Ações Estratégicas para o Enfrentamento das DCNT no Brasil 2011-2022, com os objetivos de elaborar e implementar políticas públicas efetivas e integradas, a fim de prevenir e controlar estas comorbidades e seus fatores de risco (Souza, 2021). Soma-se a isso a criação da Portaria $\mathrm{n}^{\circ} 483$ (Portaria $\mathrm{n}^{\circ} 483$, 2014), que redefine a Rede de Atenção à Saúde das Pessoas com Doenças Crônicas no âmbito do Sistema Único de Saúde (SUS) e estabelece diretrizes para a organização das suas linhas de cuidado (Marin, 2021).

Para tanto, é necessário que os serviços dos diferentes níveis de atenção (APS, secundária e terciária) estejam interligados, fazendo com que se efetivem os processos de referência e contrarreferência (Brondani et al, 2016).

$\mathrm{O}$ acesso à atenção especializada, ou à média complexidade, representa um dos principais desafios para a consolidação da integralidade da atenção no âmbito do SUS. Por esse aspecto, os sistemas de regulação desempenham papel estratégico e fundamental na organização dos fluxos entre APS e Atenção Especializada, por meio de protocolos preestabelecidos, gerenciam solicitações de exames, agendamentos, laudos e priorizando a oferta, em tempo oportuno, de acordo com critérios de gravidade padronizados (Barreto, Dias, Reis, Nunes, Lemos, \& Santos, 2021).

Outro fator, possivelmente decisivo para esta transição, é a difusão do sistema de informatização na rede do SUS, facilitando a otimização e o agendamento da demanda reprimida no sistema, e ao mesmo tempo, propiciando a capilaridade de informações nos seus diferentes níveis de atenção $\left(1^{\mathrm{a}} ; 2^{\mathrm{a}}, 3^{\mathrm{a}}\right.$, e $\left.4^{\mathrm{a}}\right)$.

Entende-se que, apesar da perpetuação de práticas voltadas para o modelo tradicional, é possível que, com o avanço de recursos tecnológicos e de práticas reflexivas no próprio cotidiano de trabalho e que integrem ensino-serviço, os gestores possam produzir um despertar pela equipe para mudança de sua prática e, consequentemente, a qualificação dos serviços de saúde (Barreto, Dias, Reis, Nunes, Lemos, \& Santos, 2021).

Pressupõe-se que a prática reflexiva acerca do processo de trabalho em saúde, tanto pelo profissional individualmente, quanto coletivamente, não seja uma constante nas unidades de saúde de atenção secundária. Mas, diferentemente, possibilita a ter maior adesão, nas unidades de atenção primária, onde o vínculo deste profissional tende a ser único, com maior tempo de permanência e de carga horária de atuação nestas unidades. Ressalta-se, que a maioria dos profissionais de saúde possui duplo vínculo de trabalho formal, muitas vezes, em razão da baixa remuneração, submetendo-se esse trabalhador a jornadas extenuantes (Barreto, Dias, Reis, Nunes, Lemos, \& Santos, 2021)

Produzem-se, por esse tipo de aprendizagem, déficits na integralidade e na resolutividade dos problemas e, neste sentido, o desafio das instituições de saúde é implementar a educação permanente como facilitadora para a resolução destes déficits, trazendo profundas transformações na política de formação dos profissionais de saúde, orientada pelos princípios do SUS e desempenhada por uma equipe de trabalho motivada para o aprimoramento da qualidade da assistência (Barreto, Dias, 
Reis, Nunes, Lemos, \& Santos, 2021).

Fundamentalmente, para que haja a concretização desta transformação no agir do profissional de saúde em seu processo de trabalho cotidiano, é necessário o entendimento da atuação interprofissional, no qual a transversalidade propicia a integralização da saúde em seus diferentes níveis de atenção.

Nesse sentido, o maior desafio posto à Política Nacional de Humanização (PNH) é articular a RAS de forma compartilhada, que garanta o acesso aos usuários com qualidade e resolubilidade, uma vez que os serviços devem servir como espaços de sociabilidade, com momentos de educação permanente (Cavalcante, Silva, Azevedo, Salomé, \& Diniz, 2015).

A Educação Permanente em Saúde (EPS) é o cotidiano do trabalho em saúde em discussão, experimentação e construção-reconstrução em tempo real, ao vivo e permanentemente. (Ceccim, 2021) Esta modalidade de educação, privilegia o processo de trabalho como eixo central de aprendizagem e utiliza-se de metodologias ativas de aprendizagem, problematizando a realidade. Logo, resulta em alternativas e soluções para os problemas reais e concretos do trabalho em saúde, auxilia na formação integral e transformação do meio, possibilita a atuação criadora e transformadora dos profissionais e não deve substituir apenas as lacunas da educação formal, mas ocupar os espaços criados pelo modelo assistencial do SUS (Farah, 2003).

Nesse contexto, sabe-se que as capacitações não contextualizadas e baseadas na transmissão de conhecimentos não são eficazes, pois contribuem muito pouco para mudanças no setor de saúde. Esses treinamentos não desenvolvem o compromisso com os princípios do SUS e não se traduzem em trabalho realizado - são prescrições de habilidades, comportamentos e perfis (Ceccim, 2021).

Ao abordarmos a Política de Educação Permanente, torna-se indispensável o entendimento do educador Paulo Freire, quando afirma que mediante a identificação de uma situação-problema, e problematizando-a entre profissionais, é possível discutir o cenário vivo do processo de trabalho, no qual a dialogicidade, permite a reflexão e a busca de resoluções para o problema identificado (Andrade, 2019).

No Brasil, a política da Educação Permanente é inserida não somente na prática em serviços da Atenção Primária. Porém, pressupõe-se que a prática da EPS na Atenção Secundária, tenha suas limitações, e mais ainda no nível terciário, hospitais (França, Medeiros, Belisario, Garcia, Pinto, Castro, \& Pierantoni, 2017). Um dos pilares de sustentação do Sistema Único de Saúde (SUS) é a formação de seus trabalhadores. Seguindo essa premissa, o Ministério da Saúde instituiu a Política Nacional de Educação Permanente em Saúde (Pneps) como estratégia de formação e desenvolvimento de trabalhadores de saúde, por meio da Portaria GM/MS nº198/2004 (França et al, 2017)

Sob esse prisma, a possibilidade de transformação do trabalho do SUS na PNEPS, ancora-se na EPS a partir de três fundamentos centrais: a micropolítica do trabalho vivo; método da roda e a problematização /aprendizagem significativa (Lemos, 2016, p. 916). Na proposta da Educação Permanente, o professor passa a ter o papel de facilitador da aprendizagem, possibilitando a construção de conhecimentos com significado para a prática diária dos profissionais de saúde. Sendo assim, o processo de ensino e aprendizagem não deve restringir-se a transferência de normas e protocolos, deve-se destacar a experiência profissional e a experiência pessoal deve ser considerada. A bagagem de conhecimentos que o indivíduo traz deve ser considerada e agregada ao desenvolvimento de um serviço de qualidade (Lemos, 2016, p. 12).

Trata-se, portanto, de um movimento coletivo, que denota a importância da interprofissionalidade em prol da qualidade da assistência em saúde. Ao abordar o termo interprofissionalidade, torna-se relevante, a princípio, diferenciá-lo de outros termos como, "multiprofissional"; "interdisciplinar" e "multidisciplinar", pois de acordo com estudos canadenses, são palavras frequentemente utilizadas na área da saúde, entretanto, algumas vezes confundidas (Almeida, Bizerril, Saldanha, \& Almeida, 2016).

A interprofissionalidade se dá através da prática colaborativa ou colaboração interprofissional. A prática colaborativa 
ocorre quando profissionais de saúde de diferentes áreas, prestam serviços com base na integralidade da saúde, envolvendo os pacientes e suas famílias, cuidadores e comunidades para atenção à saúde da mais alta qualidade, em todos os níveis da rede de serviços (Dias, Dourado, Freire, Ximenes, Da Silva, \& Gomes, 2021).

Alvarenga et al. (2013) A "multiprofissionalidade" é um conjunto de várias disciplinas, no qual cada profissional exercerá apenas seu saber especializado e o cuidado ocorrerá de forma fragmentada. Já o termo "inter”, Ceccim (2018) é definido como "a zona daquilo que há de comum entre elas ou aquele ponto de indiscernibilidade, para o qual convergem os elementos de um mesmo campo do saber, desde o qual nascem as práticas de um fazer profissionalizado". Aderir à prática interprofissional colaborativa nos serviços de saúde permite influenciar de forma sinérgica sobre o cuidado à saúde, aperfeiçoar a utilização dos recursos, aprimorar a eficiência dos serviços, apurar os resultados e racionalizar os custos na atenção à saúde ((Marco para Ação em Educação Interprofissional e Prática Colaborativa | Red Regional de Educación Interprofesional de las Américas, 2020).

Nesse interim, observa-se que no município pesquisado, a política da Educação Permanente é inserida predominantemente na prática em serviços da Atenção Primária, permitindo pressupor que a prática da EPS na Atenção Secundária, tenha suas limitações. Considerando a importância desta política pedagógica no processo de trabalho, surgem as questões norteadora deste estudo: Qual a dificuldade de implantação da Educação Permanente na Atenção Secundária na região serrana do estado do Rio de Janeiro? Quais estratégias estão sendo desenvolvidas para a inserção da Educação Permanente em Saúde na Atenção Secundária?

Nesse panorama, o objetivo deste artigo é compreender as dificuldades atribuídas a experimentação da EPS na Atenção Secundária, propor medidas para a sua efetiva implantação na teoria e na prática do processo de trabalho, e apresentar um relato de experiência da Educação Permanente na Atenção Secundária, no qual foi proposto a partir do grupo de trabalho, elaboração de protocolo de atendimento a pacientes com nível de consciência reduzido, partindo de uma demanda da unidade de saúde.

O atendimento pré-hospitalar é destinado a vítimas de traumas, violências urbanas, mal súbitos, distúrbios psiquiátricos e urgências/emergências clínicas. Visa estabilizar o paciente de forma eficaz, rápida, com equipe preparada para atuar em qualquer ambiente, removendo o paciente para unidade hospitalar. Contudo, o Brasil ainda não dispunha de um modelo autêntico de atendimento e legislação específica sobre APH. Apenas no ano de 1998, o Conselho Federal de Medicina qualifica o atendimento pré-hospitalar como serviço médico, tanto na coordenação quanto na supervisão (Resolução CFM nº.

\section{$1.529,1998)$ Revogada pela (Resolução CFM n ${ }^{\circ} 1.671,2003$ )}

Este tipo de atendimento consiste em 3 etapas:

1- Assistência ao paciente na cena (local de ocorrência);

2- Transporte do paciente até o hospital;

3- Chegada do paciente ao hospital.

Este protocolo difere ao adotar o princípio de ofertar o atendimento no local, até a estabilização inicial da vítima, sendo capacitados os profissionais, não necessariamente da saúde, mas que sejam atuantes nesta Unidade de Saúde secundária. No entanto, percebe-se que existem dificuldades que justificam a limitação da prática da Educação Permanente na Atenção Secundária. Entendendo a complexidade, no que se refere ao trabalho em equipe, a diversidade de opiniões, e o respeito a subjetividade, pretende-se focar qualitativamente na identificação de possíveis obstáculos a serem superados, permitindo a melhor prática da Educação Permanente.

Considerando que esse primeiro cuidado é um dos principais fatores que leva à redução do número de óbitos e demais complicações, sentimentos como a ansiedade podem vir atrapalhar o desempenho profissional. Assim sendo, faz-se necessário 
aprimorar a qualificação desse atendimento, a capacitação profissional, promover a busca de novos conhecimentos e estimular o profissional a manter pensamento crítico e reflexivo, visando a prestação de uma boa assistência ao paciente (Veloso et al., 2016, Rodrigues, Cortez, Almeida, \& Santos, 2020).

A proposta da EPS é provocar mudanças no processo de trabalho em saúde a partir da realidade. Por meio da aprendizagem no trabalho a EPS deve incorporar o aprender e o ensinar ao trabalho e ao cotidiano das organizações, levando em consideração os conhecimentos e as experiências que as pessoas já têm. Desta forma, a EPS pode ser entendida como aprendizagem-trabalho, no sentido de que acontece no cotidiano das pessoas e das organizações e é feita a partir dos problemas enfrentados na realidade. Propõe que os processos de educação dos trabalhadores da saúde se façam a partir da problematização do processo de trabalho, e considera que as necessidades de formação e desenvolvimento dos trabalhadores sejam pautadas pelas necessidades de saúde das populações e instituições (Lemos \& Aciole., 2018, Moretti \& Barcellos, 2020).

A EPS é dinâmica, e se altera a partir de diversos encontros, mas mantém um núcleo principal, toda prática realizada em âmbito laboral, que vise à alteração das práticas de trabalho para melhor atendimento dos usuários de um determinado sistema de saúde, tendo como foco a participação ativa dos envolvidos no processo de ensino-aprendizagem (Lemos \& Aciole., 2018, Moretti \& Barcellos, 2020).

\section{Metodologia}

Este artigo retrata um estudo descritivo, do tipo relato de experiência, vivenciado em ambulatório de cardiologia de uma Unidade de Saúde da Atenção Secundária da região serrana do Rio de Janeiro. O referido estudo encontra-se inserido no Mestrado Profissional em Ensino na Saúde: Formação Interdisciplinar para o SUS e foi organizado com o auxílio e aprovação da chefia administrativa da Unidade Secundária de Saúde, e consequente aprovação do projeto pelo Comitê de Ética em Pesquisa da Faculdade de Medicina da Universidade Federal Fluminense sob n ${ }^{\circ}$ CAAE: 31198719.1.0000.5243

Utilizou-se da metodologia de problematização com o Arco de Maguerez, estruturada em 5 etapas que se desenvolvem a partir da realidade ou de um recorte da realidade: 1) Observação da realidade; ponto-chave; 3) teorização; 4) hipóteses de solução e 5) aplicação à realidade ( prática), sendo identificado como proposta ativa e reflexiva do processo de trabalho, capaz de gerar transformação e adequado à realidade local do Posto de Saúde (Berbel, 2012 como citado em Cauduro, kindra, Ribeiro, Mata, 2017, p. 152, Freire, 2019)

Dessa forma, levando em consideração que o conhecimento pode ser construído a partir de dúvidas e dificuldades encontradas na prática, considera-se que o autor Paulo Freire, converge seus pensamentos com os preceitos da Política Nacional de Educação Permanente, pois considera que o saber não se transmite ou é pertencente a alguém, sendo utilizado como referencial filosófico nesta pesquisa (Almeida, 2016).

Em princípio, foi realizada uma reunião composta por um grupo de 15 servidores municipais, vinculados ao Posto de Saúde e diretamente envolvidos no funcionamento do ambulatório de cardiologia da Unidade, tendo como proposta inicial, um projeto piloto, visando obter avaliação quanto a necessidade e interesse relacionados a mudanças nas práticas de trabalho da Unidade de Saúde. Foi aplicado um formulário reflexivo e auto-perceptivo, relacionado ao processo de trabalho individual, elaborado pelo pesquisador, contendo as seguintes indagações: $\mathrm{O}$ que você acha de sua maneira atual de conduzir o seu trabalho? O que você faria de diferente para tornar seu trabalho mais gratificante? Qual a sua proposta de mudança para um trabalho onde haja maior integração? Você gostaria de participar de reuniões de grupo, visando a discussão do processo de trabalho interprofissional?

Observou-se neste primeiro momento, após coletado e analisado o formulário, unanimidade e interesse dos funcionários em participar das reuniões de grupo, sendo proposto a capacitação dos profissionais em relação a teoria e a prática da Educação Permanente em Saúde, como premissa e solicitação destes, para melhor compreensão do tema. Foi organizada uma pauta de 
reuniões quinzenais, com hora e tempo estipulado para início e término, obedecendo um cronograma, e mediante agendamento prévio, de forma a permitir, maior adesão e participação. Também foi apontado incentivo a discussão e identificação de uma situação-problema, correlacionada e contextualizada com a realidade local.

O instrumento de coleta de dados foi enviado a todos os 41 profissionais da saúde da Unidade (Técnicos de Enfermagem; Enfermeiros, Auxiliar administrativo; Médicos de outra especialidades; Recepcionista; Vigilante, e Administrador do Posto), mediante dados do CNES do município, visando a reflexão pessoal do processo de trabalho coletivo. Também foram incluídos os gestores da saúde (Secretário de Saúde e Sub-Secretária da Atenção Secundária). Não foi incentivada a participação de estudantes da área da saúde nas reuniões de Educação Permanente, em função das restrições impostas, decorrentes deste período pandêmico, relacionado ao SARS-COVID-19.

Não obstante, foi identificado inicialmente, o primeiro obstáculo: A alegação de um grupo de médicos, quanto ao desinteresse de participar neste primeiro momento da capacitação, em função de carga horária limitada na rede municipal, inviabilizando a participação fora do horário em sua atuação como servidor público, sendo mencionado a ausência de motivação pessoal, devido aos baixos valores de remuneração. Foram respeitados os argumentos apresentados, após escuta ativa, sendo reagendada nova data para abordagem dos conceitos de Educação Permanente.

Naquele momento, percebeu-se que seria necessário repensar a estratégia de participação dos profissionais de saúde, concluindo-se que seria possível e necessário executar as ações por etapas, começando primeiramente, pelo ambulatório de cardiologia, para depois estender aos demais segmentos da saúde da Unidade. Chegado o dia e hora agendados, realizou-se a reunião, agora apenas com o núcleo do ambulatório, com um total de 15 funcionários.

Após a identificação e esclarecimento dos termos desconhecidos, e tendo sido apresentadas as propostas de inserção da Educação Permanente, permaneceu-se por um período de aproximadamente uma hora em discussão e contextualização, considerando a realidade local do bairro, sendo identificados os nós críticos e a formulação da situação-problema, a ser discutida com base no Arco de Maguerez, partindo da realidade, buscando as hipóteses de solução para os problemas apontados por meio da teorização e reflexão, para o retorno à realidade, visando a transformação das práticas. Nas próximas reuniões, a atividade foi se desenvolvendo nos encontros em grupo, nas quais o exercício da Educação Permanente foi reconhecido como prioridade. Os funcionários que participaram da reunião de trabalho ficaram entusiasmados, frente a real possibilidade de mudança de paradigma nas condições do processo vivo de trabalho no local pesquisado.

\section{Resultados}

A elaboração de protocolo de atendimento a pacientes com nível de consciência reduzido, originou-se de demanda identificada pelo grupo de trabalho, durante as reuniões de Educação Permanente, sendo utilizado como disparador de nossos encontros, uma situação-problema vivenciada na Unidade de Saúde.

Foram programados seis encontros quinzenais, com duração de uma hora, sendo estabelecida uma pauta prévia e cronograma de atividades, permitindo ao grupo, envolvimento e regularidade às atividades. Após distribuição do Termo de Consentimento Livre e Esclarecido a todos os profissionais ativos e gestores da saúde, contou-se com a aceitação de 14 funcionários, formando desta forma, o grupo de trabalho.

Foi necessário esclarecer conceitos básicos, relacionados a inserção da EPS no SUS. Desta forma, mediante a preparação de Oficina, foi apresentado um histórico a respeito desta política nacional inserida pelo Ministério da Saúde em 2014, assim como, diferenciá-la de educação continuada, marcou o nosso primeiro contato.

Os autores (Previato \& Baldissera, 2018) compreendem que a educação continuada implica em práticas necessárias para o desenvolvimento do indivíduo, tornando-o, consequentemente, mais qualificado para atuar na sua função e na vida institucional. A educação permanente é centrada no processo de trabalho e tem como propósito melhorar a qualidade de vida humana em todas as dimensões pessoais e sociais, auxiliando na formação integral do indivíduo e na transformação do meio 
para uma futura sociedade (Silva, Pereira, \& Benko, p. 25).

$\mathrm{O} 1^{\circ}$ encontro ocorreu em meio a expectativas de todos. Foi iniciado então, percurso sugerido pelo grupo, rumo a elaboração de um protocolo, tendo sido identificada a necessidade deste, no decorrer das reuniões de trabalho. No início, a ideia era preparar um E-book narrando experiências vivenciadas no ambulatório de cardiologia. Mas, a beleza e a grandiosidade da EPS, é exatamente trabalhar a "essência do trabalho vivo", no processo dinâmico e flexível, permitindo-nos repensar o produto no qual era objeto deste estudo, e deixá-lo fluir naturalmente, sendo desenvolvido pelo grupo de trabalho, conforme os preceitos da Educação Permanente em Saúde.

$\mathrm{Na} 2^{\mathrm{a}}$ reunião, foi utilizada a metodologia ativa do Aprendizado Baseado em Problemas, criando uma situação-problema, a partir dos incidentes vivenciados naquela Unidade de Saúde, relacionados a abordagem de pacientes, excepcionalmente, que venham a ser identificados com nível de consciência reduzido, tal situação, foi utilizada como disparadora para os próximos encontros.

Após uma leitura dinâmica da situação-problema, e mediante a formação de uma "Roda de conversa", promoveu-se um "Brain Storm", estimulando os profissionais a refletirem a respeito de seu processo de trabalho. Foram repensadas as atribuições e competências regulamentadas para aquela Unidade de atenção secundária, tendo sido apontadas as questões norteadoras para reflexão. Ao final, foram estabelecidos objetivos de aprendizagem a serem alcançados em próximo encontro, seguindo os tópicos: 1- Avaliar estratégia de atendimento na Unidade com possibilidade de suporte de ambulância, em caso de urgências; 2- Verificar as competências relacionadas ao atendimento de urgência / emergência nesta Unidade de Atenção Secundária (Pesquisar Leis. RDC do Ministério da Saúde); 3- Identificar as competências necessárias para o atendimento de urgência no Posto pelo profissional de saúde, de forma a buscar capacitação destes profissionais, se necessário.

Segue a situação-problema utilizada como disparador no percurso rumo a elaboração do protocolo: Imprevistos fazem parte de nosso cotidiano...

Era o início de tarde de janeiro deste ano. O Posto estava tranquilo no horário de almoço. A maioria dos pacientes já havia sido atendida no turno da manhã, inclusive a agenda de pacientes da Cardiologia. Preparados e arrumados os consultórios, visando o atendimento da tarde, fui acionado pela recepção, alertando-me a respeito de um cidadão que aparentava não estar muito bem, encontrando-se em frente a Unidade de Saúde. O familiar havia informado que JPG, 55 anos, era portador de Diabetes Mellitus; Hipertensão Arterial, tendo sido amputada parte do membro inferior esquerdo, decorrente de complicação do Diabetes. Cadeirante. Estava se direcionando para o atendimento ambulatorial, quando apresentou um malestar súbito, segundo familiar.

Naquele momento, apesar de compromissos já agendados, e considerando a situação crítica e delicada, optou-se, por intervir. O grupo de funcionários ali presentes na unidade. Afinal, era uma questão de dignidade e respeito ao ser humano!!! Por alguns minutos, foi refletido acerca do processo de trabalho, e questionado o procedimento mais adequado a ser adotado naquele momento, de forma a proporcionar um diferencial na vida daquele indivíduo.

Imediatamente, mediante aproximação daquele indivíduo, verificou-se se tratar de uma provável urgência médica, sendo necessário deslocá-lo a um ambiente mais adequado. Assim conduzido, foi identificado um quadro de PCR (parada cardiorrespiratória). Foram momentos angustiantes, nos quais tentou-se reanimá-lo, mediante execução de manobras de massagem cardíaca externa, alternando o procedimento com alguns profissionais da área, enquanto aguardávamos a vinda de uma ambulância UTI móvel, já solicitada. Infelizmente, após a chegada do serviço de remoção hospitalar, o paciente não resistiu, vindo a óbito na unidade de atenção secundária. Esta situação, levou a equipe a alguns questionamentos: Estamos preparados para este tipo de atuação? Nos compete este tipo de intervenção? Quais equipamentos básicos estão regulamentados e aprovados para existirem em uma unidade de atenção secundária? E a equipe do Posto de Saúde, apresenta as habilidades necessárias para uma boa condução frente a estas circunstâncias? 
Mas, e agora, deveríamos preencher o atestado de óbito? A quem compete esta obrigação? Nosso posto deveria ter declarações de óbito a serem preenchidas? A médica assistente do Posto que atendera este paciente somente uma única vez, julgou necessário discutir o caso clínico com a Subsecretária de saúde, a qual foi orientada a condução do óbito ao IML (Instituto Médico Legal) da delegacia do município. Mas será que todo paciente deverá ser conduzido desta forma? Quais pacientes devem ser encaminhados para uma avaliação de autópsia? ou necrópsia, é a mesma coisa?

Todos nós que atuamos na área da saúde, somos direta ou indiretamente conduzidos a desenvolver um "olhar assistencial ‘aqueles que precisam”. Cada um de nós, tem seu papel estabelecido e sua importância para a condução e organização de um Posto de Saúde. A diferença na abordagem de profissionais frente a situações como esta apresentada, está vinculada a aquisição de competências necessárias para a execução de trabalho em equipe, com habilidades, de forma a permitir a prática assistencial com segurança, eficiência, e principalmente mais humanizada, no cenário vivo do trabalho multiprofissional, mas, principalmente atuando com interprofissionalidade.

$\mathrm{Na} 3^{\mathrm{a}}$ reunião, adotou-se a "Roda de conversa", na qual foi exaustivamente discutido e ponderado a necessidade de se buscar capacitação para os profissionais de saúde daquele Posto, relacionado àquela situação do paciente, frente as limitações dos profissionais, mas respeitando ao mesmo tempo, a identidade do Posto como unidade de atenção secundária, ou seja, referiu-se a casos de excepcionalidade, respeitando a demanda levantada pelo grupo de trabalho.

No $4^{\circ}$ encontro, mediante a formação da "Roda de conversa", surgiu finalmente uma demanda apontada por um dos participantes do grupo: Necessidade de elaboração de protocolo de assistência a pacientes com nível de consciência reduzido, excepcionalmente identificados naquela unidade. Solicitado a todos os integrantes do grupo, pesquisar e apresentar em próximo encontro, protocolos utilizados em diferentes unidades de saúde, nos seus diferentes níveis de assistência $\left(1^{\mathrm{a}}, 2^{\mathrm{a}}\right.$ e $\left.3^{\mathrm{a}}\right)$, sendo necessário adequá-lo à realidade do Posto de Saúde.

No $5^{\circ}$ encontro, mantida a formação da "Roda de conversa" finalizou-se a discussão do protocolo, sendo selecionado os parâmetros para a melhor abordagem deste paciente, respeitando a opinião dos integrantes do grupo. Neste momento, diante do material levantado nas reuniões de Educação Permanente, foi redigido e programado atividade prática, na forma de Oficina, utilizada em último encontro dos profissionais, mediante simulação prática e execução individual dos procedimentos, abordagem de urgência, podendo ser aprimorada após a sua experimentação.

\section{Discussão}

A elaboração deste protocolo, é produto obtido de reuniões de um processo de Educação Permanente, no qual foi identificado a demanda da Unidade de Saúde, vindo ao encontro com a realidade local, e mediante adequações para a sua utilização. Esta premissa baseia-se no fundamento das reuniões de EPS, que é corresponder às necessidades não somente do profissional de saúde, mas da equipe, do serviço.

Apesar da Unidade de Saúde abordada representar nível de Atenção Secundária com baixa complexidade de resolução, o incidente em questão, associado a pacientes com nível de consciência reduzido, será avaliado na condição da excepcionalidade, propiciando àquele indivíduo atendido no Posto, segurança e eficiência na execução de abordagem inicial, assim como resolutividade no que se refere ao transporte com segurança, posteriormente, a uma Unidade terciária para internação, mediante equipe capacitada.

A despeito da equipe destinada para este atendimento, ficou clara a limitação referente a administração de drogas vasoativas, e/ou antiarrítmicas, sendo exclusivamente gerenciada por profissional médico do Posto, assim como a constatação do óbito. Porém, ao enfermeiro, capacitado, é possível, destiná-lo a avaliação de nível de consciência, assim como executar manobras de ressuscitação cardiopulmonar, estando presente o médico ou não, no momento, em acordo a atuação do técnico de enfermagem, de forma a proceder de maneira sistemática e organizada, a sequência de massagem cardíaca externa, seguido de ventilação pulmonar, utilizando bolsa reservatória de oxigênio, e na ineficiência desta, a utilização de máscara laríngea, 
segundo descrição do protocolo. Estas restrições visam preservar a identidade do Posto.

Considerando a simulação prática do protocolo com os profissionais do Posto, foi possível gerar a estes confiança e equilíbrio necessários para o atendimento de usuários na unidade nesta condição de excepcionalidade. Esta constatação foi possível, mediante relato da equipe de saúde, na qual a reincidência de caso semelhante, motivou a equipe de profissionais a condução do caso de forma organizada e resolutiva, proporcionando a remoção do usuário à Unidade Terciária de forma segura e eficiente.

Da mesma forma, a experimentação prática da Educação Permanente com os profissionais do Posto de Saúde, vivenciada através da identificação de uma situação-problema, comum a todos daquela unidade, despertou a necessidade da continuidade de reuniões mensais.

Oportunamente, tivemos a inserção da informatização nesta Unidade de Saúde. A identificação desta ferramenta de trabalho, com suas facilitações e entraves, foi tema abordado em "roda de conversa". Primeiramente, foram apontados os benefícios a serem adquiridos, mediante a implantação desta metodologia de trabalho no Posto. Facilidades proporcionadas pela inovação tecnológica: Otimização da demanda reprimida na atenção secundária; Capilaridade do sistema de informatização nos diferentes níveis de abordagem de política do SUS; Maior agilidade de agendamento de exames; Maior satisfação do usuário.

O processamento automático de dados auxilia em diversas atividades, como: tomada de decisões, pesquisa, acompanhamento e resgate de informações registradas anteriormente (18).

Para os profissionais de saúde, a informação extraída por meio dos sistemas informatizados é imprescindível para o exercício do cuidado, gerenciamento e avaliação das solicitações da população. Muitas atividades desenvolvidas relacionam-se com a busca e o uso da informação, de modo que, quanto melhor o registro, armazenamento e disponibilização das mesmas, maior será a qualidade na tomada de decisão por parte destes profissionais (Marin, 2021).

\section{Prontuário Eletrônico do Paciente}

Ele consiste basicamente de um software e de um conjunto de banco de dados inter-relacionados que permitem armazenar, recuperar e analisar todos os dados clínicos gerados pela passagem do paciente no sistema de saúde, como identificação, sintomas, sinais, resultados de exames, vacinações, medicamentos, cirurgias, atendimentos ambulatoriais, internações, entre outros.

A maioria dos Prontuários Eletrônicos dos Pacientes (PEPs) mais modernos também possuem características multimídia, ou seja, podem incorporar imagens médicas, sons e sinais fisiológicos, além de textos. Assim, a tendência é de que desapareçam o papel e o filme, e que a totalidade dos dados coletados sobre os pacientes possa ser incorporada ao prontuário. O prontuário eletrônico é considerado o passo fundamental para um processo de gestão clínica eficiente.

Mas, ao mesmo tempo, também foi possível identificar as lacunas existentes, podendo representar limitações a progressão deste avanço em nosso modelo de trabalho. Dificuldades verificadas na inserção do sistema de computação na unidade: Manejo inadequado do computador; Verificação de cadastro errado, gerando demora na correção e organização do sistema; Necessidade de aprimoramento de habilidade técnica na rede de informática da Unidade de Saúde.

Os sistemas informatizados são vistos como uma tecnologia que auxilia no trabalho otimizando as atividades diárias, quando implantados sem atender as necessidades do usuário, acaba sendo uma decepção e pode ser deixado de lado, assim as informações passam a não ser alimentadas e o sistema é inutilizado. Outro fator que colabora para o insucesso no uso de sistemas informatizados na área de saúde é o desconhecimento de algumas variáveis presentes nos sistemas e que deveriam ser adequadamente alimentadas e por falta de conhecimento do usuário ou até mesmo certa desvalorização, acabam ficando em branco (Cavalcante, Silva, Azevedo, Salomé, \& Diniz, 2015). Cada vez que isto ocorre, os relatórios gerados pelos sistemas passam a ter lacunas com ausência de informações que muitas vezes, são imprescindíveis para a tomada de decisão por parte 
do profissional de saúde.

Desta forma, muitas funcionalidades presentes nos sistemas podem perder a aplicabilidade, a partir do momento que o funcionário que repassa as informações referentes ao uso do sistema não vê a necessidade de se preencher um determinado campo ou então não entendeu a maneira correta de se utilizar uma determinada função e seu preenchimento e acaba por difundir a informação sobre o uso do sistema de maneira incorreta. A omissão de informações por parte dos usuários que, muitas vezes, não compreendem a finalidade da coleta dos dados, ocasiona uma lacuna no processo analítico e decisório (Cavalcante, Silva, Azevedo, Salomé, \& Diniz, 2015).

Diante dos Prós e Contras expostos e analisados pelo grupo de trabalho, foram apresentadas as propostas visando resolutividade a esta situação-problema identificada em reunião de Educação Permanente: Capacitação dos funcionários em computação na Unidade de Saúde; Capacitação e apresentação do Organograma do SUS, visando a compreensão da Rede do SUS, em seus diferentes níveis de Atenção. Esta formação será desenvolvida na Unidade, na forma de educação continuada, proporcionando ao profissional de saúde melhor compreensão e atuação em serviço.

Após a reunião de serviço, foi obtido uma autoavaliação do grupo de trabalho em relação a prática pedagógica de Educação Permanente, no qual foi verificado, satisfação e entusiasmo na busca do aprimoramento e desenvolvimento das habilidades em serviço, sendo esta estratégia planejada e executada em reunião previamente agendada pelo setor de administração do Posto, sendo programado posterior execução da atividade.

\section{Considerações}

Capacitar equipes de saúde na Atenção Secundária, no que se refere a pacientes com nível de consciência reduzido, excepcionalmente, pode representar uma mudança de modelo na abordagem destes pacientes, propiciando-os mais segurança e eficiência quando avaliados nestes locais, gerando menor risco quanto ao seu deslocamento; reduzindo a ansiedade do profissional da saúde, revertendo aos usuários do SUS, maior satisfação.

Há necessidade de se ampliar investimentos na Atenção Secundária, de forma a entender a utilização deste protocolo em outras Unidades de Saúde, devendo ser aprimorado e aperfeiçoado, mediante a sua utilização, o que permitirá correções para a sua melhor utilidade. E ao mesmo tempo, torna-se fundamental, o incentivo a prática da Educação Permanente pelos profissionais de saúde em seus diferentes níveis de assistência, propiciando-os a atuação interprofissional que deveria ser a finalidade de qualquer grupo de trabalho vinculado ou não ao SUS.

\section{Referências}

Almeida, J. R. de S., Bizerril, D. O., Saldanha, K. G. de H., \& Almeida, M. E. L. de. (2016). Educação Permanente em Saúde: uma estratégia para refletir sobre o processo de trabalho. Rev ABENO, 16(Farah, 2003), 7-15. https://doi.org/10.30979/rev.abeno.v16i2.248

Alvarenga, J., Meira, A., Fontes, W., Burity Xavier, M., Pedroza Trajano, F., Neto, G., Silva, F., \& Almeida., F. (2013). Multiprofissionalidade e interdisciplinaridade na formação em saúde: vivências de graduandos no estágio regional interprofissional. Rev Enf UFPE on line, 7(10), 5944-5951. doi:https://doi.org/10.5205/1981-8963-v7i10a12221p5944-5951-2013

Andrade, K. G. M. (2019). A Educação Permanente em Saúde como estratégia para otimizar o sistema de regulação no município de Itaperuna-RJ [dissertação de mestrado, Universidade Federal Fluminense]. http://eeaac.uff.br/wp-content/uploads/sites/233/2020/06/KELLY-GOMES-MESSIAS-ANDRADE.pdf

Barreto, C., Dias, C., Reis, N., Nunes, A., Lemos, P., \& Santos, R. (2021). Educação permanente: perspectivas de enfermagem no contexto da atenção secundária à saúde. Revista de Enfermagem UFPE on line, 15(4). doi:https://doi.org/10.5205/1981-8963.2021.246165

Brondani, J., Leal, F., Potter, C., Silva, R., Noal, H., \& Perrando, M. (2016). Desafios da referência e contrarreferência na atenção em saúde na perspectiva dos trabalhadores. Cogitare Enfermagem, 21(4). doi:http://dx.doi.org/10.5380/ce.v21i1.43350

Cauduro, F. L., Kindra, T., Ribeiro, E. R., \& da Mata, J. A. L. (2017). Uso da problematização com apoio do Arco de Maguerez como estratégia de educação permanente para a promoção da segurança do paciente. Espaço Para a Saúde, 18(1), 150-156. https://doi.org/10.22421/15177130-2017v18n1p150

Cavalcante, R. B., Silva, J. J., Azevedo, J. A., Salomé, H.S. \& Diniz, F. A. (2015). Percepções sobre instrumentos de coleta de um Sistema de Informação. Journal of Health Informatics, 7(1). http://www.jhi-sbis.saude.ws/ojs-jhi/index.php/jhi-sbis/article/view/330 
Research, Society and Development, v. 11, n. 1, e8611124383, 2022

(CC BY 4.0) | ISSN 2525-3409 | DOI: https://dx.doi.org/10.33448/rsd-v11i1.24383

Ceccim, R. B. (2021). Educação permanente em saúde: desafio ambicioso e necessário. Comun. ciênc. Saúde, 18(5), 147-155. http://www.escoladesaude.pr.gov.br/arquivos/File/textos\%20eps/educacaopermanente.pdf

Dias, S., Dourado, B., Freire, C., Ximenes, L., Da Silva, L., \& Gomes, P. (2021). Educação permanente, interprofissionalidade e práticas colaborativas na atenção à saúde. Rev Ext Ação, 20(5), 71-81. https://doi.org/10.32356/exta.v20.n2.43767

Farah, B. (2003). Educação em serviço, educação continuada, educação permanente em saúde: sinônimos ou diferentes concepções? Revista APS, 6(5), 123125, https://www.ufjf.br/nates/files/2009/12/Tribuna.pdf

França, T., Medeiros, K. R. de, Belisario, S. A., Garcia, A. C., Pinto, I. C. de M., Castro, J. L. de, \& Pierantoni, C. R. (2017). Política de Educação Permanente em Saúde no Brasil: a contribuição das Comissões Permanentes de Integração Ensino-Serviço. Ciência \& Saúde Coletiva, 22(6), 1817-1828. https://doi.org/10.1590/1413-81232017226.30272016

Freire, Paulo. Pedagogia do Oprimido. 67. ed. Rio de Janeiro; São Paulo: Paz e Terra, 2019.

Lemos, C. L. S. (2016). Educação Permanente em Saúde no Brasil: educação ou gerenciamento permanente? Ciênc. saúde colet., 21 (3), 913-922. https://doi.org/10.1590/1413-81232015213.08182015

Lemos, F. M., \& Geovani G. A. da S. (2018). Educação Permanente em Saúde: o estado da arte. Rev. Interdisciplin. Promoç. Saúde - RIPS, Santa Cruz do Sul, 1(3), 207-213

Marco para Ação em Educação Interprofissional e Prática Colaborativa Red Regional de Educación Interprofesional de las Américas. (2020). Educacioninterprofesional.org. https://www.educacioninterprofesional.org/en/node/47

Marin, H. F. (2021). Sistemas de informação em saúde: considerações gerais. Journal of Health Informatics, 2(Ceccim, 2021). http://www.jhisbis.saude.ws/ojs-jhi/index.php/jhi-sbis/article/view/4

Moretti, M. M. S., \& Barcellos, R. de A. (2020). Rodas de conversas como estratégia de educação permanente em saúde na construção de protocolo assistencial. Research, Society and Development, 9(8), e112985395. https://doi.org/10.33448/rsd-v9i8.5395

Portaria n ${ }^{\circ}$ 483, de $1^{\circ}$ de abril de 2014. (2014, 1 abril). Redefine a Rede de Atenção à Saúde das Pessoas com Doenças Crônicas no âmbito do Sistema Único de Saúde (SUS) e estabelece diretrizes para a organização das suas linhas de cuidado. Gabinete do Ministro.

Previato, G. F., \& Baldissera, V. D. A. (2018). A comunicação na perspectiva dialógica da prática interprofissional colaborativa em saúde na Atenção Primária à Saúde. Interface (Botucatu), 22(suppl 2), 1535-1547. https://doi.org/10.1590/1807-57622017.0647

Resolução CFM nº 1.529 de 28 de agosto de 1998. (28 de agosto, 1998). Dispõe sobre a regulamentação do atendimento pré-hospitalar e dá outras providências. Conselho Federal de Medicina.

Resolução CFM no .1 .671 de 9 de julho de 2003. (9 julho, 2003). Dispõe sobre a regulamentação do atendimento pré-hospitalar e dá outras providências. Conselho Federal de Medicina.

Rodrigues, G. V. B., Cortez, E. A., Almeida, Y. S. de, \& Santos, E. C. G. dos. (2020). Educação permanente em saúde nos serviços de urgência e emergência: uma revisão integrativa. Research, Society and Development, 9(8), e14985269. https://doi.org/10.33448/rsd-v9i8.5269

Silva, M. J. P., Pereira, L. L., Benko, M. A. (1989). Educação continuada: estratégias para o desenvolvimento do pessoal de enfermagem. Saraiva.

Souza, J. C. B. de (2021). Desenvolvimento de uma ferramenta computacional para avaliação da assistência hospitalar a partir de indicadores de qualidade. [dissertação de mestrado, Universidade de São Paulo] https://teses.usp.br/teses/disponiveis/82/82131/tde-28032016-145950/pt-br.php

Veloso, L. U. P., Laurindo, L. M. B., Sousa, L. R. P., Veloso, C., Silva Junior, F. J. G., \& Monteiro, C. F. S. (2016). Prevalência de ansiedade em profissionais de enfermagem de urgência e emergência. Revista de Enfermagem UFPE on line, 10(11), 3969-3976. Retrieved Dec 19, 2019, https://periodicos.ufpe.br/revistas/revistaenfermagem/article/download/11479/13329 